\title{
Short Communication:
}

\section{A survey of important decisions and settings needed for attaining a sustainable world}

\author{
Nils O. Larsson \\ Gothenburg, Sweden \\ skolnils@tele2.se
}

The following short communication is directed to the main subject of this issue of the JOURNAL OF SOCIOCYBERNETICS the matter of Sustainable Development. My remarks are based upon a methodology which I have presented earlier (cf. Larsson 1997; 2000). The main objective of the methodology is to find the most important decisions within a specific area of discussion. Focussing on the important decisions and in which settings they are taken gives an increased possibility of solving the problems in question. In this actual subject the analysis should cover decisions on all levels i.e. individual, informal and formal groupings of people, nations, group of nations as well as decisions on the global level. As the subject is very extensive in this paper I will present only some of the more important problems.

In order to find the most important decisions I will use the following structure:

1. What is the goal of the analysis?

2. What are the most important factors for attaining this goal?

3. What decisions are influencing these factors?

4. What information and decision perspective is needed

5. Creation of a decision hierarchy

6. What organizations should take these decisions? 


\section{Goal}

To create the outlines of a system for a sustainable world.

\section{Most important factors}

In order to handle the complexity of the problem the analysis must be limited to the most important factors in a long as well as short time perspective. I have in this problem found the following factors to be most important:

a. Sustainability of renewable resources

b. Sustainability of non-renewable resources

c. Factors controlling human population's growth

d. Introduction of new technology and its influence on sustainability

A general requisite for the analysis of these factors is to find the means for inducing citizens and nations to a sustainable behaviour such as economic and other incitements for the individual coupled with guidelines for the activities of all sorts of organizations.

\section{Decisions for a sustainable world}

By analyzing which decisions are connected to the above factors one can get the fundamentals for a creation of a decision system and decision hierarchies. For each group of factors the decisions are grouped in the decision makers' level from the individual to the global level. For many decisions there are no actual decision taken at the highest levels but the indication should be regarded as an indication of a necessity to create such a decision making system.

As the conditions for decision making, due to technical utilities and increased knowledge, are becoming more and more complex, there is a need for a continuous overview of decision rules and organizational structure. Thus these rules should not be too sustainable. In order to create a sustainable world the rules should not be sustainable but flexible. (Beer, 1994). 


\section{a) Sustainability of renewable resources}

Renewable resources are such as water, air, soil and those living systems that are dependent on these elements as human beings, all animals such as birds, fish, and insects and vegetation. The ability for renewal is based on an ecological balance where the renewing factors are in balance with the exploiting factors.

The sustainability is threatened by overexploitation when the renewing factors are reduced or eliminated e.g. by pollution of water and soil. Another problem is the effect that cultivation of fish has on the wild fish resources. In this area there is also a lack of relevant information for maintaining an ecological balance e $\mathrm{g}$ about the long time effects of various cultivating methods. Overexploitation of diminishing resources is also caused by the increase in human population when more and more areas are exploited for human settlements.

Here follows some examples of the decisions concerned:

\section{Individual}

Choosing ecological products for consumption

Cultivating one's own need of vegetables

\section{Nations}

Introducing laws against pollution

Taxation on non-ecological products

Subventions on ecological products

\section{International organizations}

Introducing voluntary restrictions against pollution in air and all fishing waters

Introducing ecological products

\section{Global organizations}

Introducing laws against pollution of air and water

Defining ecological products 
Comment: Restrictions against pollution have been introduced in many countries but there are also many areas where there is a need for introduction of international/global restrictions as air and water have in most cases no national borders.

\section{b) Sustainability of non-renewable resources}

Mineral oil, gas and metals are the main resources within this category. By definition these resources will be exhausted sooner or later depending on the rate of consumption, discovery of new deposits, and the development of technologys for a more efficient usage. In the long run alternative sources must be found. Another problem, connected to the consumption of these type of resources, is the side-effects as pollution and its sideeffects on the climate, which strengthen the arguments for reducing this consumption.: Another important factor is the threatening climate change and its implications for the consumption of energy resources.

Here are some examples of decisions for these factors

\section{Individual}

Choice of transport means (private car, public transport etc)

Decision to travel

Choice of destination

\section{Nations}

Investments in infra-structure as roads, railways, airports

Taxation of consumption of non-renewable resources

Initiating research of alternative sources of energy

\section{International organizations}

Opening new sites of extraction

Introducing new transport products using renewable energy sources

Global organizations

Extraction fees to the community 
Laws concerning control of extraction

Taxation of consumption of non-renewable resources

Comment: In this area extraction fees seems to be necessary and these fees must be decided and collected by a global organization which at present does not exist.

\section{c) Factors controlling human population's growth}

The above factors are both strongly dependent on the growth of the human population in number well as in age distribution. The analysis can be split up on following factors:

- Number of children born

- Death rate for children

- Average length of life

- Number of non-active people that has to be cared for

A complicating fact is that there are great variations of these figures between countries, Western industrialised world, developing countries and regions. This fact can cause strain in the community when actions must be taken.

The most important decisions for this factor on each level:

\section{Individual}

Deciding to have child

Suicide

Health care organizations

Decisions for prolonging life

Decisions for shortening life

\section{Nations}

Restrictions on number of children allowed (ex China)

Religious rules forbidding use of contraceptives 
Nils O. Larsson

\author{
Health activities \\ Helping people die (allowed or not allowed) \\ Starting war / stopping war
}

\title{
Global \\ UN:s health activities \\ UN's peace activities
}

Comment: As can be seen from the above decisions this is a very delicate problem. Until now the discussion has focussed on the theory that a higher standard of living will reduce the birth rate. Even if the birth rate is reduced the increased standard of living and thus an increased consumption per capita will maintain or increase the overall high consumption of all sorts of resources. As a consequence the consumption in the richer countries must be reduced to maintain a balance. This may be the most crucial problem to solve in order to get a sustainable world. This unbalance also exists within individual countries such as Sweden between closely and sparsely populated areas.

\section{d) Introducing new technology and its influence on sustainability}

Our economic system favours the development of new products with an ever shorter life time. During the last century many new technologys have been developed and we usually regard this development as positive. This view is founded on our common measure of economic progress (GNP) with its limitation that I will elucidate later. There are however also some negative consequences concerning sustainability that must be considered.

If the sustainability factors were to be considered when developing new products there should be an evaluation of negative as well as positive consequences of the introduction and marketing. In the absence of a relevant measure of sustainability performance only the positive factors are measured. Some of the factors are:

- Life length of products and cost of maintenance

- Marginal cost effects of new technology and its costs of scrapping products using old technology.

- Cost for change of routines due to new products.

- Consequences for educational programs and generation gaps in experience. 
Some products, as medicine, favours the long time usage as the development time and costs are considerable.

Some products as mobile phones may create problems in a long perspective but the research around the usage have not given any clear answer and the more the usage is spread around the world the bigger will the consequences be if one should detect some negative effects resulting in an increased resistance against change.

One dominant solution to some problems can cause vulnerability to the effects of environmental problems as the actual ash clouds from an Icelandic volcano has created for the European airline systems. Thus several different solutions should be favoured.

Decisions of interest are the following:

Individual

Buying new things or repairing

Choosing means of physical communication

Choosing heating alternatives

Organizations within a state

(Same as for the individual)

Installing devices for exhaust cleaning (water, smoke etc)

Choice of research objects

Investing in research areas

Nations

Taxes on fuel

Taxes on pollution

Taxation of investment of new technology that is not required for improving resource utilisation.

Choice of research objects

\section{Global organizations (incl companies)}

Replacing old technology with new technology 
Comment: This is a very controversial area as inventions and developing new products are in general regarded favourable. One crucial factor in the above decisions is if the new product contributes to a sustainable world more than the costs created in scrapping the former products. In this connection the labour costs have increased in the Western industrialized nations which has caused most of the labour intensive industry to move to nations as China and India. Service must be close to the customer and this has made the costs of service and maintenance so expensive that in the choice between buying new products or repairing the decision tends to favour the buying alternative. This decision is important in a sustainable world perspective and needs a deeper analysis.

\section{What information is needed for making relevant decisions?}

It would carry to far to analyze the information requirement of every single decision above but some general requirements will be presented.

The information needed is to a large extent dependent on the perspective to be applied in the actual decision moment. Another problem is the need for economic relevant information about the costs involved as there is in most of the relevant decisions a need for considering the costs of the various factors involved. Some of the costs that must be considered is the cost of fuel and mineral consumption. In this connection there is a need for an alternative economic measure in order to consider the long term consequences of the various factors. The information requirements should also consider the impact of the actual decision on other possible measures for inducing citizens and nations towards a sustainable behaviour. The existing measure of GNP (Gross National Product) is misleading as it does not reflect, for example, the degradation of the environment, the depreciation of natural resources or declines in individuals' quality of life (Vickers, 1972). The first and last factors are difficult to quantify whereas the depreciation of natural resources should be possible to quantify and to put a price on, at least theoretically. In practice it will be problematic to decide on rules that will be accepted globally. This will require some form of global government or authority that can decide on and enforce these rules. A decision hierarchy covering all levels is needed. 


\section{Creation of a decision hierarchy}

As it is impossible, or at least very difficult for the individual, to consider a global perspective in all his/her decisions a decision hierarchy is needed. (Ahl et al, 1996) Decisions at the highest level must have a global perspective combined with a global responsibility. These decisions should serve as guidelines for the lower levels to consider in their respective decision activities. All activities that have an influence on the global sustainability should be included in the global hierarchy. However, many industrial organizations have during the latest decades become more and more internationalized and as such not part of any formal hierarchy outside their own organization. Consequently, they can move to avoid national laws and restrictions and also activities from labour union activities with their national limited perspective. This has resulted in a movement of industries from the western nations to nations as China and India where labour is considerably less costly.

\section{Which organization should take these decisions?}

There is a need for an organization with global authority that could enforce its decisions on group of nations, individual nations, organizations and individuals at the lower levels.

Such an organization is at present not existing even if the United Nations can fill some of these duties. One difficult problem in this connection is how detailed the rules and guidelines should be at each level. Another difficult problem is how the leaders of these organizations should be selected.

What type of leadership is needed to create such a decision hierarchy? Some research has been made e.g. Przeworski (2000) but he has used the degree of economic development as a measure of success. The problem in this connection is that the usual measure of economic development (e.g. GNP) is not a relevant measure of neither national and global economy nor of sustainability as I have indicated above.

Besides hierarchies, can we as individuals be inclined to change our behaviour in order to create a sustainable world?

Perhaps based on some form of global "religious" movement? 


\section{References}

Ahl. Valeri and T F H Allen, (1996): "Hierarchy Theory, A Vision, Vocabulary and Epistemology", Columbia University Press, New York

Beer, Stafford, (1966, 1994): "Decision and Control", John Wiley \& Sons Ltd, Chichester, UK

Larsson, Nils O. (2000): "Various System Levels need Various scientific methods", Paper presented at the $2^{\text {nd }}$ International Conference on Sociocybernetics, Panticosa, Spain

Larsson, Nils O. and Malmsjö, A (1997): "A Model for design of Human Activity Systems”, Systemic Practice and Action Research, 11(4), 455-479

Larsson, Nils O. (1999): “A Metamodel for Designing Human Activity Systems - An Analysis of Psychiatric Care in Sweden”, Proceedings of the ISSS's 1999 Conference at Asilomar.

Larsson, Nils O. (2000): "Decision Settings Analysis - a tool for analysis and design of human activity systems", Theory and Decision, 49 no 4. 339-360

Przeworski, Adam et al, (2000): "Democracy and Development”, Cambridge University Press, Cambridge, UK

Vickers, Geoffry, (1972): “Freedom in a Rocking Boat”, Penguin Books 